\section{Noticias} y comentarios

\title{
Las señas de identidad de Huesca a través de la imagen
}

La Diputación Provincial de Huesca inició la recuperación de fondos fotográficos en 1989 con la adquisición de 4.000 placas del fotógrafo Ricardo Compairé Escartín (1883-1965) y con la creación de la Fototeca Provincial. En los primeros años se recopiló la obra de afamados pireneístas como Lucien Briet, Fritz Krüguer, Soler y Santaló, se recuperó la obra de los primeros fotógrafos altoaragoneses como Andrés Burrel y se inició un fructífero camino de colaboración con distintas entidades públicas y personas particulares.

Siguiendo la misma línea de trabajo, en el ahora llamado Archivo de la Fotografía e Imagen del Altoaragón se han ido incorporando fondos transcendentes para la provincia como los de Lorenzo Almarza, Ricardo del Arco, Alfonso Foradada, Joaquín Galán, Feliciano Llanas, José Oltra, Vicente Plana o Ildefonso Sanagustín, además de numerosas copias de colecciones fotográficas particulares hasta llegar a sumar más de 60.000 registros fotográficos. Conscientes del valor de la imagen en movimiento, en el último año han ingresado más de 500 películas, en distintos soportes, realizadas por altoaragoneses o que versan sobre la provincia de Huesca.

Todo este importante cúmulo patrimonial va a ver la luz en el programa Signos de la Imagen. Signos fue el nombre que la Diputación Provincial dio a un programa que nacía con la vocación de recuperar y difundir las señas de identidad, las señales históricas, los hitos del pasado de la provincia de Huesca. Su primera edición en 1993 tuvo como referente el arte y la cultura en el Alto Aragón medieval y, al año siguiente, los siglos XVI y XVII. En este año, desde el mes de marzo hasta el mes de mayo, son la fotografia, el cine y el vídeo los protagonistas de estos signos de la imagen, cuyo argumento principal continúa siendo el territorio del Alto Aragón.

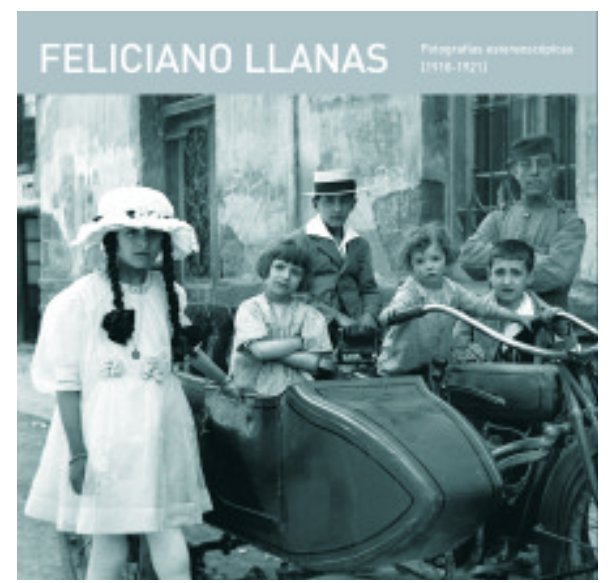

Las ciudades de Huesca, Barbastro y Fraga son los escenarios de la secuencia de ocho exposiciones colectivas e individuales y de ocho montajes cinematográficos que vertebran el programa general, diseñado con el ánimo de profundizar en el conocimiento de autores y obras, así como en la renovación de planteamientos en la lectura de las imágenes.

La exposición Signos de la imagen en Huesca, ubicada en la propia sede de la Diputación, es el eje central del programa. Su comisaria, Chus Tutelilla, no nos muestra la historia de la fotografía y del cine en Huesca, sino una secuencia visual cuyo principal argumento es convocar vestigios de historias, deseos y sueños de quienes, desde su capacidad para verlos, anotarlos y desvelarlos, dieron luz a nuevas formas de ver, saber y ser. En la reunión de esta pluralidad de ecos visuales, así como en la organización de su recorrido expositivo, no se han seguido criterios estrictos de ordenación clasificatoria según las nociones de cronología o de género que, además de revelarse insuficientes, hubieran etiquetado en exceso lo que se pretende sea una secuencia sensible, abierta, capacitada para restituir a cada imagen sus múltiples dimensiones y para potenciar las relaciones con el resto de las imágenes en exposición. El territorio de la provincia de Huesca es el argumento principal de esta narración visual, articulada en capitulos de recorrido interrumpido por el tiempo inestable y discontinuo que es propio de las imágenes.

La labor de recuperación del patrimonio fotográfico se da a conocer exponiendo tres de los fondos más significativos que han ingresado en el Archivo de Fotografía e Imagen del Altoaragón en los últimos años.

El primero es el de José Oltra, fotógrafo que, con su padre, mantuvo el gabinete profesional de más larga vida de la capital (1916-1981) por el que pasó gran parte de la sociedad oscense para retratarse. Mucho menos conocida es su producción más personal sobre temas como el montañismo, el motociclismo o sobre momentos como la proclamación de la república y la guerra civil, con el largo asedio de Huesca que él vivió y fotografió desde dentro de la ciudad. Ildefonso San Agustín (Huesca, 1882-1946) se reunía con excelentes fotógrafos como Rodolfo Albasini, Ricardo Compairé, Fidel Oltra, Enrique Dücker y los hermanos Viñuales. Sus fotografías de paisajes y excursiones reflejan su etapa como miembro activo de la sociedad Turismo del Alto Aragón. También realizó fotografías de monumentos y piezas de valor histórico, artístico y etnográfico de la provincia de Huesca y destacó como retratista y reportero urbano 


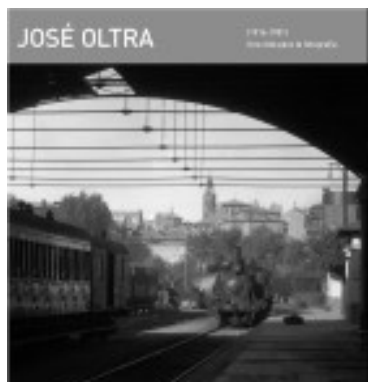

durante los años de la Dictadura de Primo de Rivera. A pesar de que cerca de la mitad del fondo se perdió en un incendio, lo conservado supone un referente gráfico indispensable para la historia de Huesca en los años 20 del pasado siglo. Feliciano Llanas (Fonz, 1880-1936) pudo iniciarse en la fotografía con Nicolás Viñuales, excelente fotógrafo aficionado de Huesca. Sobre todos los temas que le interesó fotografiar, la familia ocupa el lugar privilegiado, pero también fotografió parajes montañosos, que destacan por su singular profundidad, o sidecares, autobuses, coches, tractores y aviones en convivencia con los carros tirados por mulas. Interesantes son las fotografías que realiza en el laboratorio de la Facultad de Ciencias de Zaragoza y, en especial, las del director del mismo, doctor Rocasolano, con su microscopio. Como contraste a la actividad científica se conservan fotografías sobre las labores del campo y a la vida militar. El formato estereoscópico de sus fotografías es un atractivo añadido a su exposición y catálogo.

El comisario Ángel Fuentes en la exposición Guerra Civil: puntos de vista reflexiona sobre cómo un fotógrafo profesional y un soldado generan registros diferentes de una misma posición o de un mismo hecho de armas: unos fotografían la guerra que el mundo ve, otros su mundo en guerra. La suma de ambos puntos de vista guarda la memoria de un conflicto que para muchos se decidió en las tierras de Huesca.

La exposición Panorámica y paisaje: imagen y cultura en Huesca (1850-2006), comisariada por Virginia Espa, presenta una colección de panoramas, panorámicas y vistas panópticas del territorio altoaragonés y trata de la evolución de las técnicas y de los soportes fotográficos, como puede apreciarse en la muestra de cámaras panorámicas de la colección Boisset-lbáñez, y del progresivo enriquecimiento de la mirada sobre el territorio, es decir, de la formación de nuestra noción de paisaje.

La recuperación del patrimonio audiovisual se articula en ocho secciones, organizadas con criterios temáticos o cronológicos, en las que se da a conocer una amplia muestra de lo que autores altoaragoneses o de fuera, profesionales o aficionados, han filmado en la provincia de Huesca. La selección ha supuesto un exhaustivo trabajo de búsqueda a través de filmaciones realizadas por entes públicos, como NO-DO y RTVE, o privadas, en la actualidad conservadas en filmotecas, fundaciones e institutos. Otra línea de búsqueda ha sido la de los propios realizadores, quienes en ocasiones nos han llevado a otros nuevos. La recopilación ha supuesto visionar más de 500 trabajos. Cabe destacar la presentación de la versión restaura- da de la película de Antonio de Padua Tramullas Revista de Huesca 1914.

Signos de la imagen no se queda tan sólo en la recuperación y difusión del patrimonio fotográfico y audiovisual sino que incorpora también las creaciones de autores contemporáneos. La exposición Fotografía en la Escuela de Arte en Huesca muestra la obra de cinco jóvenes artistas formados en la Escuela de Arte de Huesca. La enseñanza de la fotografía se demuestra eficaz cuando el trabajo del alumno, como ocurre con el caso de Begoña Cisneros, Laura Covarsí, $\mathrm{M}^{\mathrm{a}}$ Ángeles Cuartero, Antonio Lachos y Rebecca Muttel, se alía con la intuición y ese "modo de mirar" tan particular que les identifica y les hace diferentes. También se muestra la obra de la artista aragonesa Lara Almárcegui (Zaragoza, 1972), que goza en la actualidad de la máxima atención internacional, con una selección de algunas de las intervenciones más destacadas que ha realizado en los últimos años en la exposición Pabellón ruina, que toma su nombre de una construcción erigida con motivo del programa en un carrascal a las afueras de Barbastro. Y la de artistas como Javier Codesal, Enrique Carbó o David Rodríguez cuyas obras se integran en distintas exposiciones.

A falta de una valoración definitiva del impacto del programa, ya que alguna exposición se prolonga hasta el mes de mayo, Signos rinde cuentas a la sociedad del trabajo realizado en la recuperación del patrimonio fotográfico y audiovisual en la provincia de Huesca. También representa un ejemplo de colaboración entre las instituciones y los ciudadanos: gran parte de los fondos seleccionados para las exposiciones han sido depositados en la Diputación por particulares, hecho que demuestra una creciente sensibilización de la ciudadanía hacia la conservación de su patrimonio.

Lejos de ser un capítulo cerrado, Signos de la Imagen es el inicio de un camino donde otros investigadores deberán incidir con nuevos descubrimientos y nuevas interpretaciones de estas señas de identidad. Además nos queda la labor de reordenar todos los fondos existentes y describirlos adecuadamente para ponerlos a disposición de nuestros usuarios.

José Miguel Pesqué Lecina Jefe de la Sección de Cultura. Diputación Provincial de Huesca 